\title{
EDITORIAL
}

\section{The APT online discussion forum}

\section{David Cottrell}

The centre of College guidance on continuing professional development (CPD) is the personal development plan (PDP), which provides a framework for proactive development (Royal College of Psychiatrists, 2001). Attendance at CPD events will be driven by previously agreed learning objectives rather than by the attractiveness of the latest conference advertisement to be received. The same guidance advises psychiatrists to use Advances in Psychiatric Treatment (APT) as part of their CPD strategy, but how can a journal be part of an individual reader's proactive and planned set of learning objectives unless that reader can influence the content of the journal?

This issue of APT sees the first fruits of an attempt to forge a more interactive relationship with our readership by enabling such influence.

FOCUS is a strategic dissemination project established by the College Research Unit to promote effective practice in child and adolescent mental health services (CAMHS). As part of its mission an e-mail discussion list has been established (http:// www.mailbase.org.uk/lists/focus), allowing group communication over the internet. Any professionals involved in CAMHS may join (contact catherine. ayres@virgin.net) and membership currently stands at several hundred.

Last year, the Editorial Board of APT posted a message on the FOCUS discussion list asking for suggestions for review articles, also in the child and adolescent mental health field. This generated more than 40 suggestions and considerable discussion, in the online forum, about the relative merits of these suggestions and requests for contributions by specific authors. As a result, 15 articles have been commissioned, the first of which, on psychopharmacology in CAMHS, appears in this issue (Coghill, 2003).

How well these articles are received remains to be seen but this is a genuine attempt to allow readers of an academic journal to dictate its content. Much has been written about the use of computers and computer-based learning in medicine, but so far this has tended to focus on the development of computerbased learning packages for teaching on specific topics. For some journals, articles which have been submitted are now posted on the internet for online refereeing and discussion, but opportunities for other types of interaction between readership and editorial board seem less common. Two recent reviews of computer-based learning did not mention this possibility (Parkin, 2000; Greenhalgh, 2001).

The APT online discussion forum can be accessed at http://www.rcpsych.ac.uk/bulletin/apt/index. html. Readers can comment on articles they have read and enter into discussion about them with others. A searchable archive of past issues has been available for some time and this can be browsed by topic. The new online discussion forum includes a top-ten list of the most frequently accessed articles and a chance to nominate favourites that readers would encourage others to read. There is also a virtual suggestions box where readers can nominate subjects for articles and/or authors from whom they would like to see articles commissioned.

It is interesting to speculate about features that might become possible with today's technology. A more sophisticated grouping of articles according to subject could enable related articles to be accessed with one click. A facility could be provided for readers to attach comments to archived articles enabling access to comment, discussion and updates about published items.

If $A P T$ is to continue as a key part of CPD strategy for psychiatrists, it will have to become more responsive to the needs of its readers. Not all of the ideas above will necessarily come to fruition, but some will. The Editorial Board is interested in hearing from readers about their ideas for development. If you have any comments, log on to the APT discussion forum website and post a message.

David Cottrell was appointed to the Foundation Chair in Child and Adolescent Psychiatry at the University of Leeds in 1994 (Academic Unit of Child and Adolescent Mental Health, University of Leeds, 12A Clarendon Road, Leeds LS2 9NN, UK). He is currently Director of Learning and Teaching at the School of Medicine in Leeds, where he has responsibility for all learning and teaching activities in the School. His research interests are in the adaptation of children and families to chronic illness and in the evaluation of child and adolescent mental health services and educational interventions. 


\section{References}

Coghill, D. (2003) Current issues in psuchoopharmacology for child and adolescent psychiatrists: part 1. Advances in Psychiatric Treatment, 9, 86-94.
Greenhalgh, T. (2001) Computer assisted learning in undergraduate medical education. BMJ, 322, 40-44.

Parkin, A. (2000) Computers in clinical practice: applying experience from child psychiatry. BMJ, 321, 615-618.

Royal College of Psychiatrists (2001) Good Psychiatric Practice: CPD (Council Report CR90). London: Royal College of Psychiatrists.

\section{OUT NOW FROM GASKELL}

\section{MCQs in Psychiatry}

By David McNamara

Practising multiple choice questions is a superb way to reinforce knowledge.

This book contains some 600 questions covering all the sub-specialities of psychiatry. It is intended for use in conjunction with the College Seminars series and will be of great benefit to all trainees and established clinicians. The book will enable users to identify gaps in their learning and to consolidate their knowledge and understanding of psychiatry.

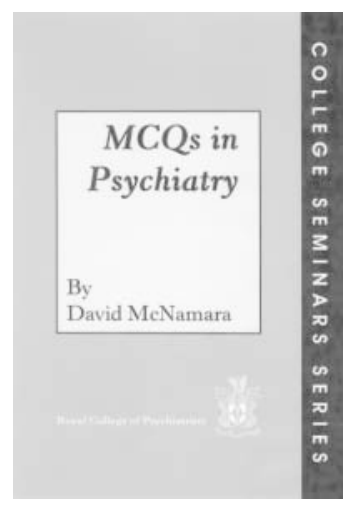

March 2003, 256pp, Paperback, ISBN 1901242 89 7, Price £18.00

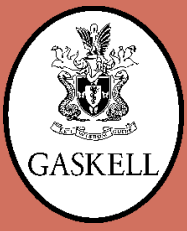

AVAILABLE FROM:

Book Sales, Royal College of Psychiatrists,

17 Belgrave Square, London, SW1X 8PG, United Kingdom.

Tel: +44 (0)2072352351 Ext 146. Fax: +44 (0)2072451231. Order online on our website: www.rcpsych.ac.uk 